\title{
The 1997/98 Summer Rainfall Season in Southern Africa. Part II: Model Simulations and Coupled Model Forecasts
}

\author{
BRADFIELD LYON AND SIMON J. MASON \\ International Research Institute for Climate and Society, Columbia University, Palisades, New York
}

(Manuscript received 21 April 2008, in final form 21 January 2009)

\begin{abstract}
This is the second of a two-part investigation of rainfall in southern Africa during the strong El Niño of 1997/98. In Part I it was shown that widespread drought in southern Africa, typical of past El Niño events occurring between 1950 and 2000, generally failed to materialize during the 1997/98 El Niño, most notably during January-March (JFM) 1998. Here output from three atmospheric general circulation models (AGCMs) forced with observed sea surface temperatures (SSTs) and seasonal forecasts from three coupled models are examined to see to what extent conditions in JFM 1998 could have potentially been anticipated.

All three AGCMs generated widespread drought conditions across southern Africa, similar to those during past El Niño events, and did a generally poor job in generating the observed rainfall and atmospheric circulation anomaly patterns, particularly over the eastern and southern Indian Ocean. In contrast, two of the three coupled models showed a higher probability of wetter conditions in JFM 1998 than for past El Niño events, with an enhanced moisture flux from the Indian Ocean, as was observed. However, neither the AGCMs nor the coupled models generated anomalous stationary wave patterns consistent with observations over the South Atlantic and Pacific. The failure of any of the models to reproduce an enhanced Angola low (favoring rainfall) associated with an anomalous wave train in this region suggests that the coupled models that did indicate wetter conditions in JFM 1998 compared to previous El Niño episodes may have done so, at least partially, for the wrong reasons. The general inability of the climate models used in this study to generate key features of the seasonal climate over southern Africa in JFM 1998 suggests that internal atmospheric variability contributed to the observed rainfall and circulation patterns that year. With the caveat that current climate models may not properly respond to SST boundary forcing important to simulating southern Africa climate, this study finds that the JFM 1998 rainfall in southern Africa may have been largely unpredictable on seasonal time scales.
\end{abstract}

\section{Introduction}

As reported by Lyon and Mason (2007, hereafter Part I), the tendency for warm-season rainfall in southern Africa to be below average during El Niño events is a well-documented phenomenon (Mason and Jury 1997; Mason and Goddard 2001), with two of the worst regional droughts of the twentieth century associated with the El Niño episodes of 1982/83 and 1991/92 (Rouault and Richard 2003). As such, the absence of the development of widespread drought across southern Africa during the strong 1997/98 El Niño was a notable exception to the more typical ENSO response.

Corresponding author address: Dr. Bradfield Lyon, International Research Institute for Climate and Society, 61 Route 9W, P.O. Box 1000, Columbia University, Palisades, NY 10964-8000. E-mail: blyon@iri.columbia.edu
In Part I, results of an observational analysis indicated that the season of January-March (JFM) 1998 showed the largest departure in seasonal rainfall from past El Niño events in southern Africa during the second half of the twentieth century. The atmospheric features associated with this departure in behavior included an unusually strong Angola low, which favored the transport of moisture into southern Africa from the tropical continental interior and the formation of tropical temperature troughs, both of which are conducive to enhanced rainfall in southern Africa (Todd and Washington 1999; Cook et al. 2004; Reason and Jagadheesha 2005). The enhanced Angola low appeared to be associated with an anomalous wave train extending across the South Pacific and Atlantic Oceans and was possibly enhanced locally by anomalously high sea surface temperatures (SSTs) off the Angolan coast (Reason and Jagadheesha 2005). An enhanced flux of moisture into 
southern Africa from the tropical western Indian Ocean, particularly in January 1998, was also observed on the eastern flank of the Angola low. Significantly enhanced moisture flux (and rainfall) in East Africa during the 1997/98 El Niño was associated with a strong Indian Ocean dipole event, with SST anomalies exceeding three standard deviations along the equatorial east coast of Africa. Overall, the observational analysis suggested that the primary factors associated with the wetter-than-typical JFM 1998 rainy season were the anomalous stationary wave pattern in the Southern Hemisphere and its connection to the enhanced Angola low, and, at least for part of the season, an enhanced moisture flux into southern Africa from the western Indian Ocean during a year with an exceptionally strong Indian Ocean dipole event.

The main objective of the current study is to investigate the extent to which the failure of widespread drought to develop in JFM 1998 was potentially foreseeable through an analysis of output from three atmospheric general circulation models (AGCMs) forced with observed SSTs and seasonal hindcasts generated by three coupled models. While attributing specific behavior in the models (or observations) to physical causes (e.g., boundary forcing from a specific region) goes beyond the scope of the study, various model fields are compared with observed conditions to examine the extent to which regional and large-scale atmospheric circulation features are in agreement. For example, if modeled rainfall across southern Africais found to generally capture the observed pattern, were the modeled and observed atmospheric circulation features also similar, or would the models have gotten the "correct" rainfall response for the "wrong" reason(s)?

As in Part I, the primary season of focus is JFM 1998, with the general land area of interest being the subcontinent of Africa from $15^{\circ} \mathrm{S}$ to the southern coast of South Africa. To the extent that the AGCMs respond realistically to the boundary forcing of the observed SSTs, and to the extent that the wetter-than-typical conditions in southern Africa in JFM 1998 were indeed related to such boundary forcing, the model simulations will provide some indication of potential predictability. For example, the very large, positive SST anomalies observed in the far-western Indian Ocean in JFM 1998 were far from typical of other El Niño events of the past $50 \mathrm{yr}$. The coupled model forecasts in turn allow for the potential importance of coupled atmosphere-ocean processes (again, to the extent these are realistically captured by the models) to be considered as a potential factor in generating the observed conditions in JFM 1998. The comparison of hindcasts with simulations does carry a few caveats. For example, the initial atmospheric conditions in the AGCMs were set at the start of the simulation runs (i.e., around 1950), whereas the coupled model forecasts were initialized in November 1997 and are therefore subject to initialization shocks. However, the forecasts examined here in the coupled models are for the JFM season, giving considerable time for such shocks to abate.

The paper is structured as follows. The data and methodology used in the analyses are described in section 2. Modeled rainfall in southern Africa for JFM 1998 and JFM of seven prior El Niño events is reported in section 3 for the individual AGCMs and coupled models. Low-level atmospheric circulation anomalies in each model are considered in section 4 with modeled, anomalous upper-level stationary-wave behavior reported in section 5. An overall discussion and the main conclusions of the study are detailed in section 6 .

\section{Data and methodology}

\section{a. Data}

The AGCMs used in the study are the Community Climate Model (CCM) version 3.6 from the National Center for Atmospheric Research (NCAR; Kiehl et al. 1998), ECHAM version 4.5 (Roeckner et al. 1996), and the Experimental Climate Prediction Center (ECPC) model from the Scripps Institution of Oceanography, a modified version of the National Centers for Environmental Prediction (NCEP) AGCM (Kanamitsu et al. 2002). Using observed SSTs, simulation runs for each of these models have been previously generated using different initial atmospheric conditions to create 24, 24, and 10 ensemble members for the ECHAM, CCM, and ECPC models, respectively. Model runs covering the period of 1959-2000 are used here. Monthly and seasonal anomalies in all model simulation fields are computed from a 1961-90 period mean to be consistent with Part I, which avoids having the two largest El Niño events of the past century in the same climatological base period. The spatial resolution of output from the CCM and ECHAM models is roughly $2.8^{\circ}$ latitude $\times 2.8^{\circ}$ longitude and $2.5^{\circ}$ latitude $\times 2.5^{\circ}$ longitude for ECPC.

The three fully coupled ocean-atmosphere models used are from the Development of a European Multimodel Ensemble System for Seasonal-to-Interannual Prediction (DEMETER) project (Palmer et al. 2004). The specific models are from the Met Office (UKMO), Météo-France, and the European Centre for MediumRange Weather Forecasts (ECMWF). Seasonal forecasts for JFM made from November start times were used for the period of 1959-2000. Nine ensemble members were available for each coupled model forecast, 
with each forecast run having slightly different initial atmospheric and oceanic conditions. Monthly and seasonal anomalies in coupled model forecast fields for JFM were computed as the difference from the mean of all forecasts made in November from 1961-90. The spatial resolution of the data analyzed from all three coupled models is $2.5^{\circ}$ latitude $\times 2.5^{\circ}$ longitude.

The station-based global precipitation analyses produced at the Climate Research Unit (CRU), University of East Anglia (New et al. 1999, 2000, 2001) were the primary source of monthly rainfall data, which are on a $0.5^{\circ}$ latitude $\times 0.5^{\circ}$ longitude grid. The Climate Prediction Center (CPC) Merged Analysis of Precipitation (CMAP) merged gauge and satellite-estimated rainfall product (Xie and Arkin 1996) was utilized, which consists of monthly gridded analyses for the globe $\left(2.5^{\circ}\right.$ latitude $\times 2.5^{\circ}$ longitude resolution $)$ and covers the period of 1979-2007. While readers are referred to Part I for comparisons of model runs with observations, a few analyses from the NCEP-NCAR reanalysis project (Kistler et al. 2001) are presented here to emphasize specific points. As mentioned in Part I there are some concerns about data quality in the NCEP-NCAR reanalysis for the Southern Hemisphere, especially prior to the assimilation of satellite information. However, emphasis is placed on the El Niño events of 1982/83 and $1997 / 98$ when these data are most reliable. All of the data used in the study were accessed online via the IRI Data Library (http://iridl.ldeo.columbia.edu/).

\section{b. Methodological approach}

For most of the region, the main rainy season is from October to March. The main season of interest here is JFM because it is the season during 1997/98 when rainfall departed most significantly from the typical El Niño response in southern Africa. In addition, as discussed in Part I, the second half of the rainy season in southern Africa also shows different characteristics from those of the first half. For example, in the subtropics, zonal moisture fluxes are generally found to be more important during the early part of the rainy season (October-December), with meridional fluxes acquiring greater importance later in the season (D'Abreton and Lindesay 1993). For comparison with the 1997/98 episode, seven earlier El Niño events identified by Part I were used, namely, the JFM seasons of 1966, 1969, 1973, 1983, 1987, 1992, and 1995. The principal analysis technique employed here to determine the atmospheric response in the models is through composites.

With observed climatological rainfall having substantial spatial variation across southern Africa, and because amplitude biases in model precipitation are well known, the metric used here to evaluate seasonal rainfall variability across southern Africa is based on terciles. To do so, in both the models and observations, terciles were determined from a simple ranking of JFM precipitation, at each grid point, over the 1961-90 base period. The relative severity of dry conditions across southern Africa was then measured as the percent of grid points below the lowest tercile across all land areas in southern Africa south of $15^{\circ} \mathrm{S}$. For reference, the spatial distribution of grid points with observed JFM precipitation below the lowest tercile for 1998 and the median of the seven past El Niño events (excluding 1998) are shown in Fig. 1. Hereafter the percentage of grid points across the southern Africa land area with rainfall below the lowest tercile is referred to as percent dry area $(P D A)$.

Computing PDA instead of comparing observed and modeled rainfall amounts at matching gridpoint locations helps reduce the effect of any systematic spatial biases in model precipitation. In addition, the main objective of this study is to examine the extent to which the models generated unusually dry conditions across southern Africa generally, without necessarily emphasizing specific subregions where it did or did not develop. Of course, to be useful in the current analysis each of the models needed to exhibit skill in generating the observed temporal variability in PDA. Temporal correlations between time series (1961-2000) of PDA in models and observations for JFM (not shown) indicated that all six models exhibited statistically significant skill in this regard at the $95 \%$ confidence level, with correlation values ranging from roughly 0.4 to 0.6 .

\section{Modeled PDA for past EI Niño events and for JFM 1998}

Using all ensemble members of the model simulations and coupled model forecasts, probability density distributions of the PDA were computed for each model for the seven El Niño events occurring prior to 1998 and 10 near-neutral ENSO years. ${ }^{1}$ Because PDA is bounded between 0 and 100 , these distributions were fit by a beta distribution with the parameters computed using the method of moments based on values of the mean and standard deviation of the PDA computed across all ensemble members for each model. These distributions are shown as solid (for past El Niño events) and dashed (for ENSO-neutral years) lines in Figs. 2 and 3, where a similar methodology was also used to compute the probability distributions of the AGCM and coupled

\footnotetext{
${ }^{1}$ The 10 years were the JFM seasons of 1960, 1961, 1963, 1979, 1980, 1981, 1984, 1990, 1994, and 2002.
} 

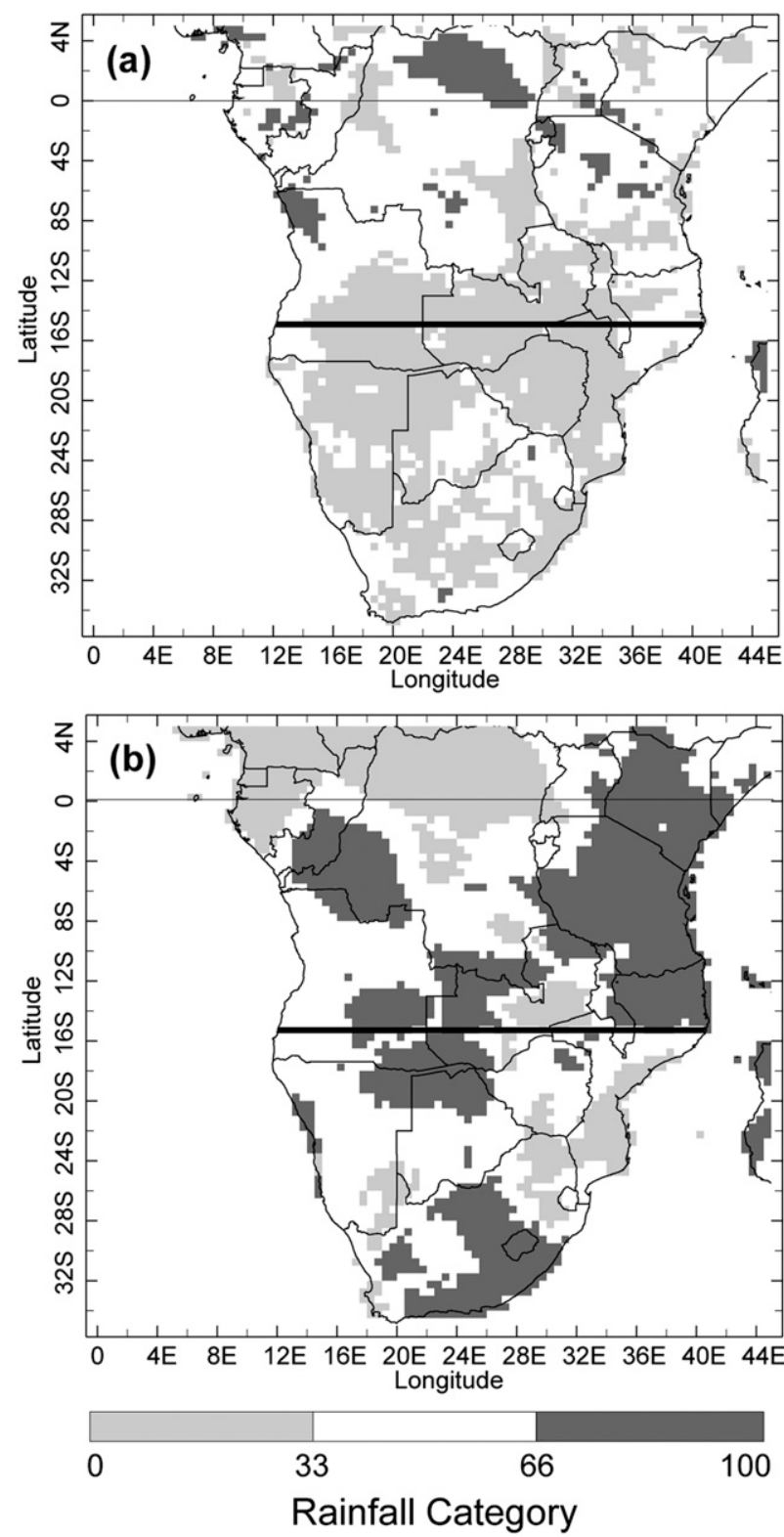

FIG. 1. (a) Median JFM precipitation in tercile classes for seven El Niño events (excluding 1998), and (b) rainfall in tercile classes for JFM 1998.

model runs. These distribution plots were overlain with the individual ensemble members of the various models (vertical bars in Figs. 2 and 3) for the JFM 1998 runs with both sets of distributions normalized to have a maximum value of 1 . The mode of the smoothed PDA distributions for the seven El Niño events in all six models was found to be relatively close to the observed mode of the PDA, which was 52\% (for JFM 1998 it was observed to be only $18 \%$ ). The differences in model PDA distributions for the seven El Niño years and 10 non-ENSO years were also statistically significant for all
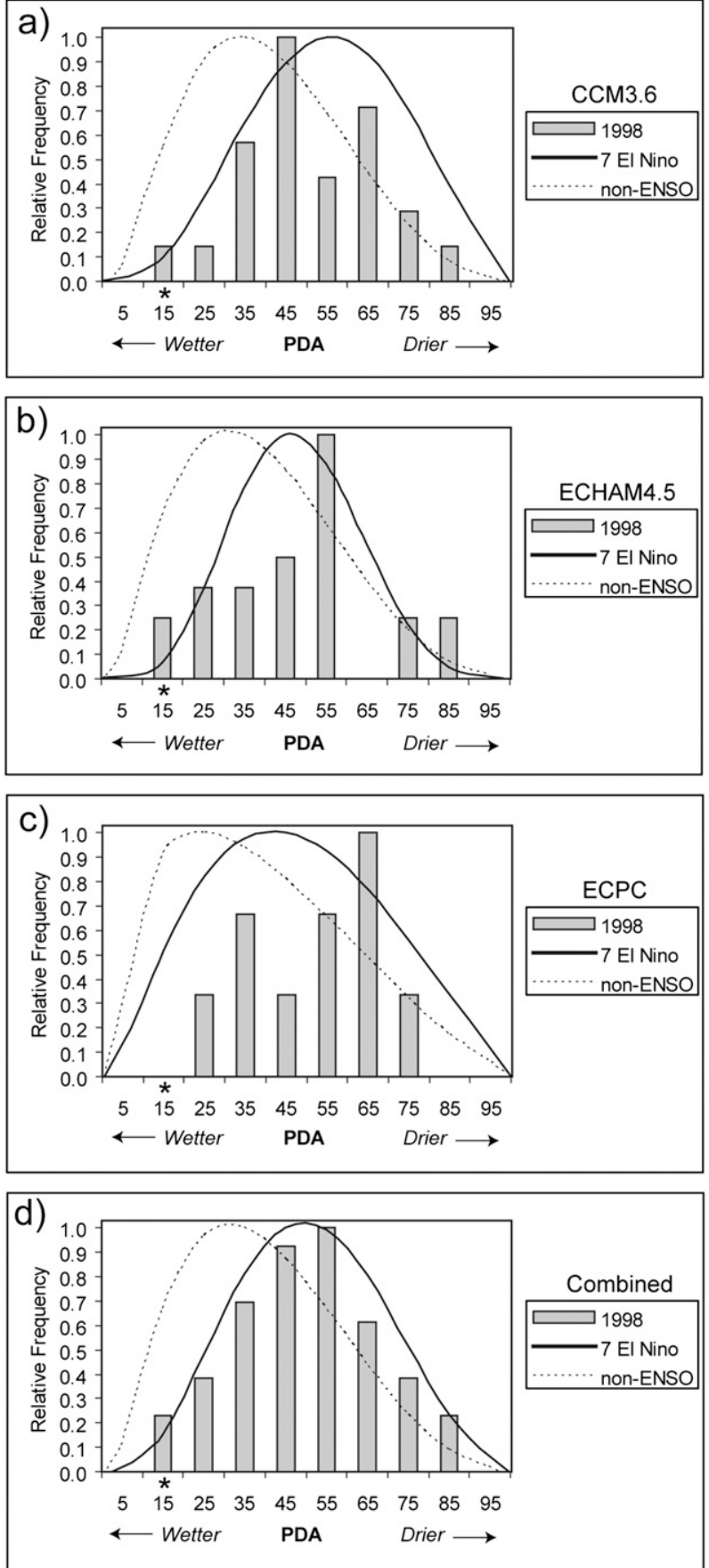

FIG. 2. (a)-(c) The relative frequency (normalized to have a maximum of 1) of PDA in southern Africa during the JFM season based on output from three AGCMs for seven El Niño events (solid lines), 10 non-ENSO years (dashed lines), and JFM 1998 (bars). (d) The same distributions, but for the combined ensemble members from all three models. The asterisks indicate the observed PDA value in JFM 1998. 

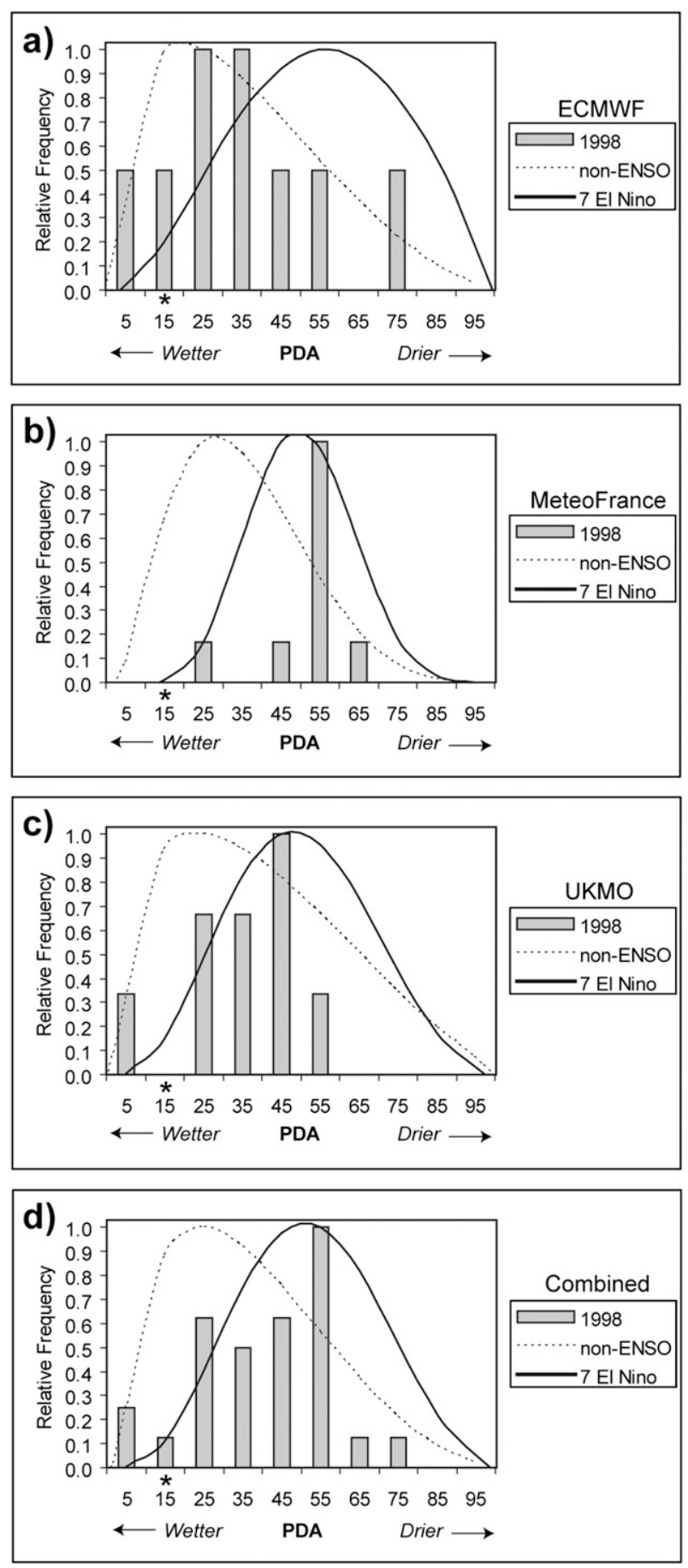

FIG. 3. As in Fig. 2, but for the coupled model forecasts.

models ( $p$ value $<0.05$ ) based on a KolmogorovSmirnov (KS) test (Sheskin 2007).

For JFM 1998 the AGCM runs forced with observed SSTs all generally indicated PDA distributions similar to those for the seven prior El Niño events. This tendency can be seen most clearly in Fig. 2d, which shows the combined results for all three AGCMs. Only 3 of the 58 AGCM ensemble members (roughly $5 \%$ ) across all three AGCMS generated a PDA value either at or below what was observed in JFM 1998 (noted by asterisks at the class mark of $15 \%$ on each panel in Figs. 2 and 3). On the other hand, the coupled model forecasts, particularly from the ECMWF and UKMO models, tended to shift the PDA distributions toward lower values (i.e., wetter conditions). While in the same direction to what was observed in JFM 1998, only three ensemble members (about 11\%) generated a PDA value at or below that observed. Nonetheless, a KS test indicates the differences in the distributions in Fig. 3d (combined coupled models) for JFM 1998 versus the seven prior El Niño events were statistically significant. In short, the AGCM simulations did not indicate a decrease in the probability of drought in comparison to seven past El Niño events, while the combined (and two of the three) coupled models showed an enhanced probability of somewhat wetter conditions. The AGCM results suggest that the observed conditions in JFM 1998 may not have been primarily the result of anomalous surface boundary forcing (SSTs), or that the models were not able to generate the appropriate response if they were. The slight increase in the likelihood of lower PDA (wetter conditions) by the coupled models compared with past El Niño events could conceivably implicate the importance of coupled atmosphere-ocean processes in generating the observed rainfall in southern Africa in JFM 1998. However, the coupled models may also have tended toward wetter conditions as a result of anomalous circulation features in the models that were not realistic vis-à-vis observations. Thus, the anomalous atmospheric circulations generated by the models (for both AGCM and coupled runs) for JFM 1998 were examined to see how closely they reproduced the observed conditions reported by Part I.

\section{Anomalous low-level atmospheric circulation}

\section{a. Anomalous regional moisture flux}

The ensemble average, anomalous 850-hPa moisture fluxes and precipitation in tercile classes (over land) for JFM 1998 are shown in Fig. 4 for the AGCMs. In all three models southern Africa has substantial land area below the lowest tercile of rainfall, consistent with the PDA distributions shown earlier. None of the models generate the anomalous Angola low seen in the observations and the associated anomalous moisture flux into southern Africa from the tropical continental interior (cf. Part I, Fig. 3a), which suggests that the enhanced Angola low observed in JFM 1998 was not forced by the 
(a) $\mathrm{CCM} 3.6$

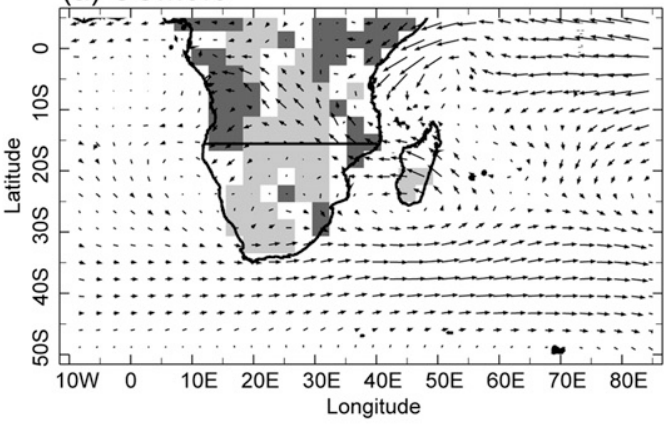

(b) ECHAM4.5

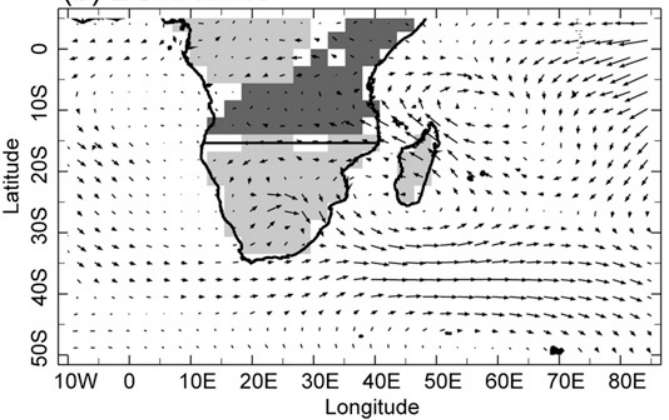

(c) ECPC

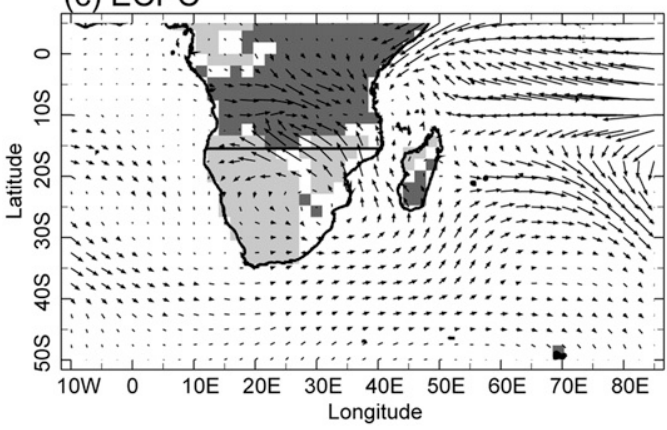

(d) OBS

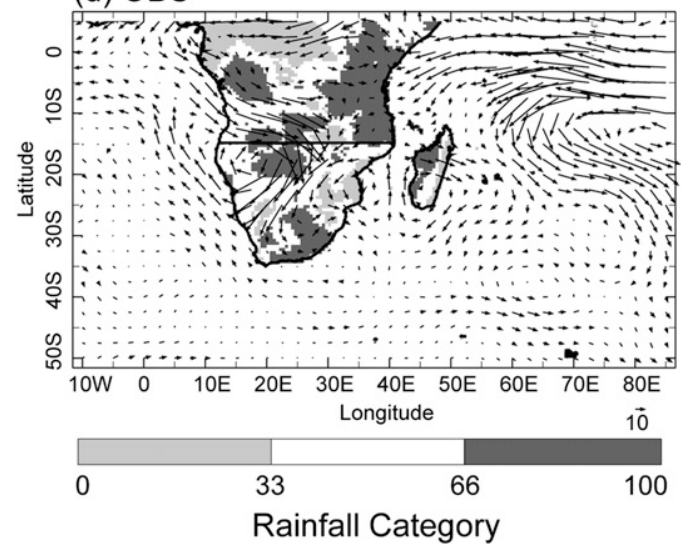

FIG. 4. Ensemble-mean 850-hPa anomalous moisture flux vectors (units: $\mathrm{kg} \mathrm{kg}^{-1} \mathrm{~m} \mathrm{~s}^{-1} \times 10^{3}$ ) for JFM 1998 along with rainfall in tercile categories in model simulations from the three AGCMs and in observations. Dark horizontal lines on the plots indicate $15^{\circ} \mathrm{S}$. observed SSTs (or the models are not responding properly to the observed SSTs if it was). However, as shown later (in section 5), the enhanced "Angola low" in JFM 1998 appears to be a circulation feature associated with an anomalous wave train that extends across the South Atlantic, indicating the importance of remote forcing. The AGCMs did generally simulate the enhanced rainfall in tropical East Africa that was observed, although the anomalous moisture flux patterns over the Indian Ocean show considerable variation among the models. All three AGCMs generate a northwestto-southeast-oriented confluence zone southeast of Madagascar, which is typical of El Niño events, but the southern branch (to the south and east of Madagascar) is much too strong relative to the observations.

In the coupled models (Fig. 5) generally higher rainfall is generated over southern Africa than in the AGCM simulations, particularly in the ECMWF and UKMO models. The latter two models also show enhanced moisture flux into the eastern sections of the southern Africa region from the western Indian Ocean north of Madagascar. None of the coupled models, however, generate the anomalous Angola low and its associated anomalous moisture flux from the tropical continental interior. As in the AGCMs the coupled model forecasts also generate enhanced rainfall in tropical East Africa, although not (in 2 of the 3 models) as far south as that observed. All three models do generate confluence zones in the anomalous moisture flux field to the southeast of Madagascar, although again the southerly branch of this feature is too strong relative to what was observed.

\section{b. Low-level, large-scale atmospheric circulation anomalies}

The moisture flux anomalies in Figs. 4 and 5 were related to the low-level anomalous atmospheric circulation by examining standardized anomalies of the departure in $850-\mathrm{hPa}$ geopotential heights from their zonal mean, shown in Fig. 6 for JFM 1998 in the AGCMs. Again, the enhanced Angola low seen in the observations is absent in the simulations, with other notable differences as well. In particular, the AGCMs do not extend the anomalous ridge over the southern Indian Ocean nearly as far westward as observed, and each of the models generates an anomalous cyclonic circulation to the southeast of Madagascar (centered near $45^{\circ} \mathrm{S}$, $70^{\circ} \mathrm{E}$ ), which was not identified in the observations. Taken together, these features in the AGCMs reduced the anomalous moisture flux into southern Africa from the western Indian Ocean and continental interior, relative to observations, thus favoring unusually dry conditions. Differences between modeled and observed 
(a) ECMWF

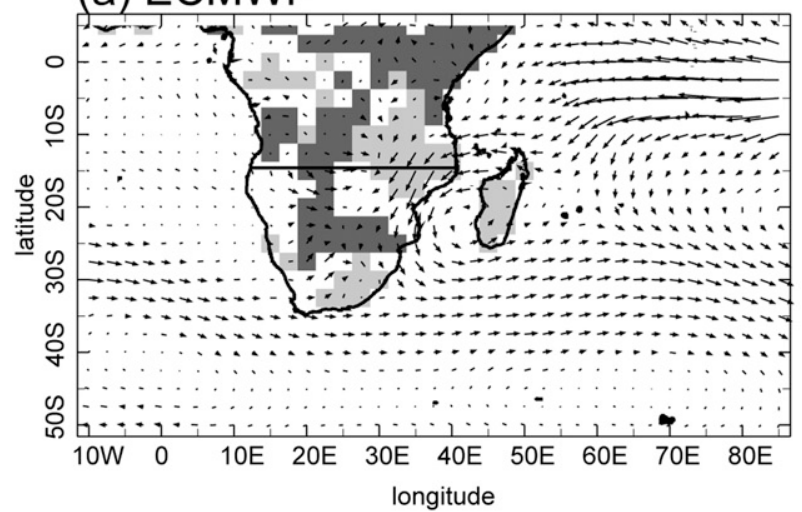

(b) MeteoFrance

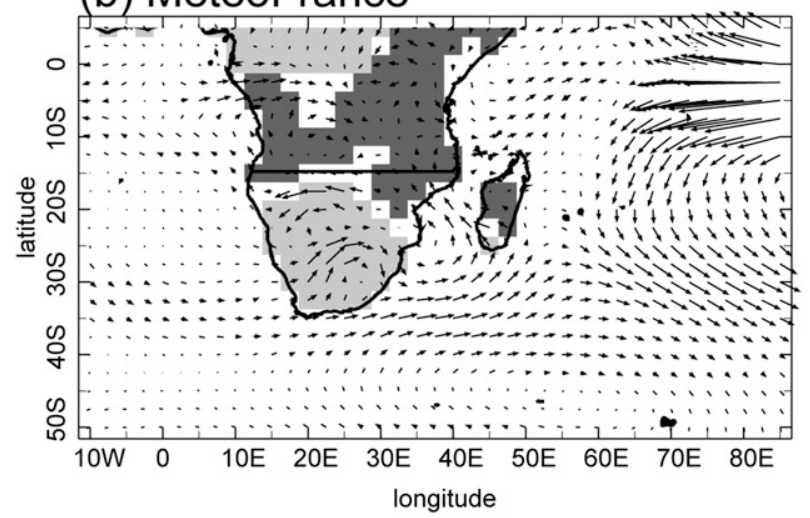

(c) UKMO

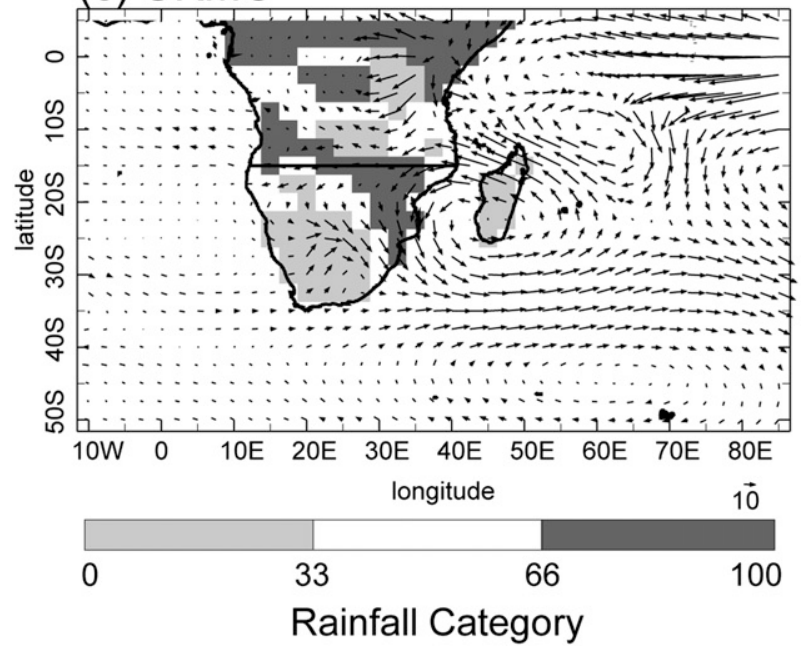

FIG. 5. As in Fig. 4, but for the coupled model forecasts.

anomalous circulation patterns over the South Pacific and Atlantic Oceans are further discussed in section 5.

The coupled models also failed in generating an anomalous Angola low in JFM 1998 (Fig. 7), although the two "wetter" models for southern Africa (ECMWF and UKMO) did generate generally weak, anomalous cyclonic circulations across the region. These same two models also performed better than the AGCMs in extending an anomalous ridge across the Indian Ocean toward Madagascar, favoring the observed increase in moisture flux into southern Africa as noted earlier. Similar to the AGCMs, however, all three coupled models also generated anomalous cyclonic circulations to the southeast of Madagascar, which were not seen in the observations. Thus, while two of the coupled models appear to have more realistically captured the anomalous atmospheric circulation over the Indian Ocean in JFM 1998 relative to the AGCMs, the anomalous stationary wave patterns across the South Atlantic and Pacific were, like in the AGCMs, quite different from the observations. These anomalous wave patterns are considered in greater detail in both sets of models in the following section.

\section{Anomalous upper-level stationary waves}

Stationary wave patterns were investigated by examining anomalies in the difference in $200-\mathrm{hPa}$ geopotential height from their zonal averages. In addition, the horizontal components of the anomalous stationary wave activity flux vector (Plumb 1985) were computed for the JFM season. This flux $\mathbf{F}_{\mathbf{s}}$ may be written as

$$
\mathbf{F}_{\mathbf{s}}=p \cos \varphi\left[\begin{array}{l}
\bar{v}^{* 2}-\frac{1}{2 \Omega a \sin 2 \varphi} \frac{\partial\left(\bar{v}^{*} \bar{\Phi}^{*}\right)}{\partial \lambda}, \\
-\bar{u}^{*} \bar{v}^{*}+\frac{1}{2 \Omega a \sin 2 \varphi} \frac{\partial\left(\bar{u}^{*} \bar{\Phi}^{*}\right)}{\partial \lambda}
\end{array}\right],
$$

where the overbars represent time averages (a season) and the asterisks are departures from the zonal average. Also, $\Phi$ is geopotential height, $u$ and $v$ are the zonal and meridional components of the $200-\mathrm{hPa}$ wind, respectively, $\Omega$ is the angular velocity of rotation, and $a$ is the mean radius of the earth. The derivative terms are longitude $\lambda$, latitude $\varphi$, and pressure $p$. Here the anomalous flux is considered, so the variables in Eq. (1) are seasonal average anomalies. Plumb (1985) showed that for steady, conservative waves $\mathbf{F}_{\mathbf{s}}$ is nondivergent, and for slowly varying, almost plane waves, $\mathbf{F}_{\mathbf{s}}$ is parallel to the group velocity. For seasonal averages where time variations are considered small, anomalous wave sources (sinks) are associated with regions where $\mathbf{F}_{\mathbf{s}}$ is divergent (convergent). Because the flux is based on quasigeostrophic assumptions, it was not computed at latitudes equatorward of $10^{\circ}$. While the climatological stationary waves have greater amplitude in the winter season, $\mathbf{F}_{\mathbf{s}}$ has been successfully used as a diagnostic in summer season analyses in both the Southern (Berbery et al. 1992) and Northern (Lyon and Dole 1995) Hemispheres. 
(a) CCM3.6 $850 \mathrm{hPa}$

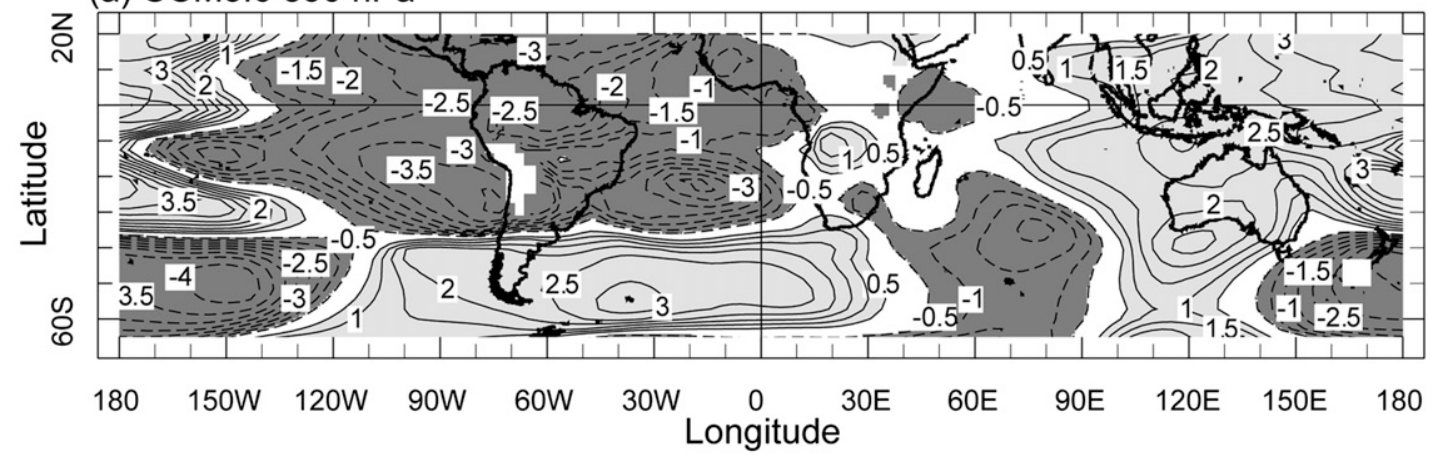

(b) ECHAM4.5 $850 \mathrm{hPa}$

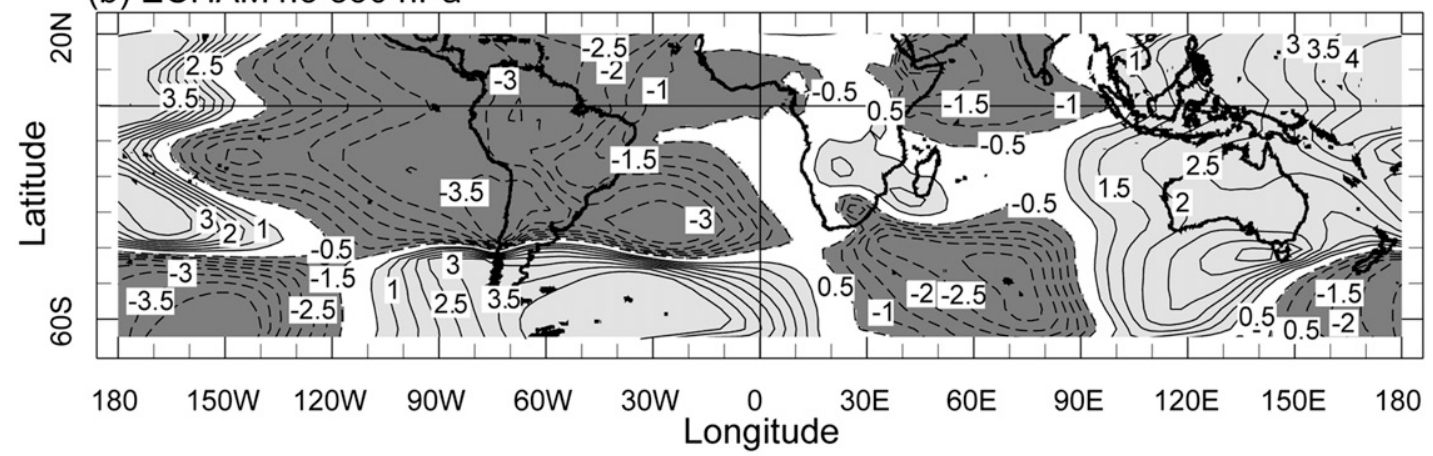

(c) ECPC $850 \mathrm{hPa}$

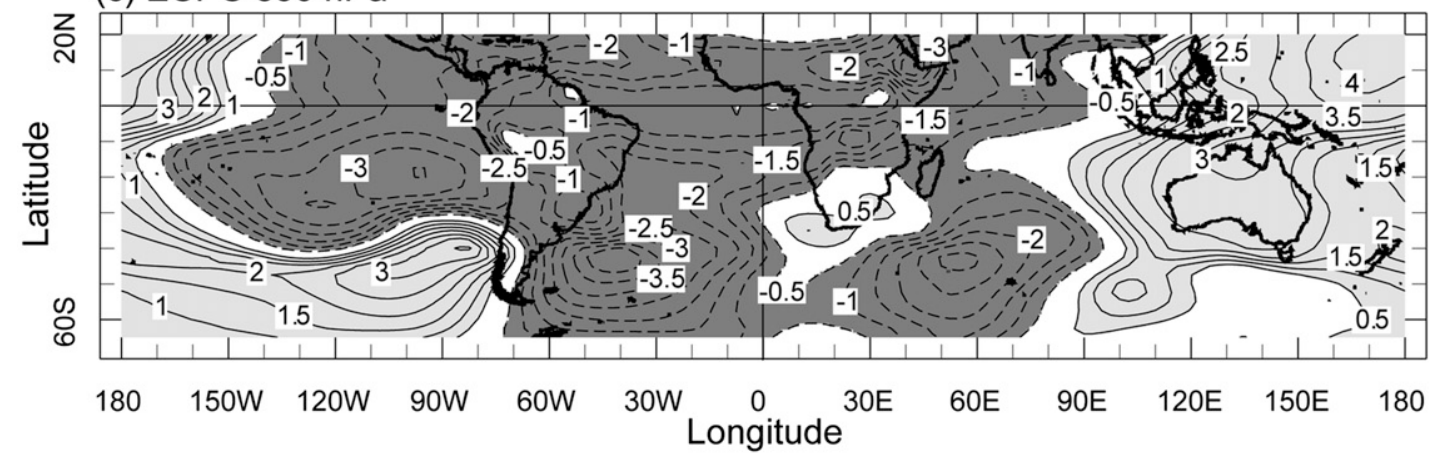

(d) OBS $850 \mathrm{hPa}$

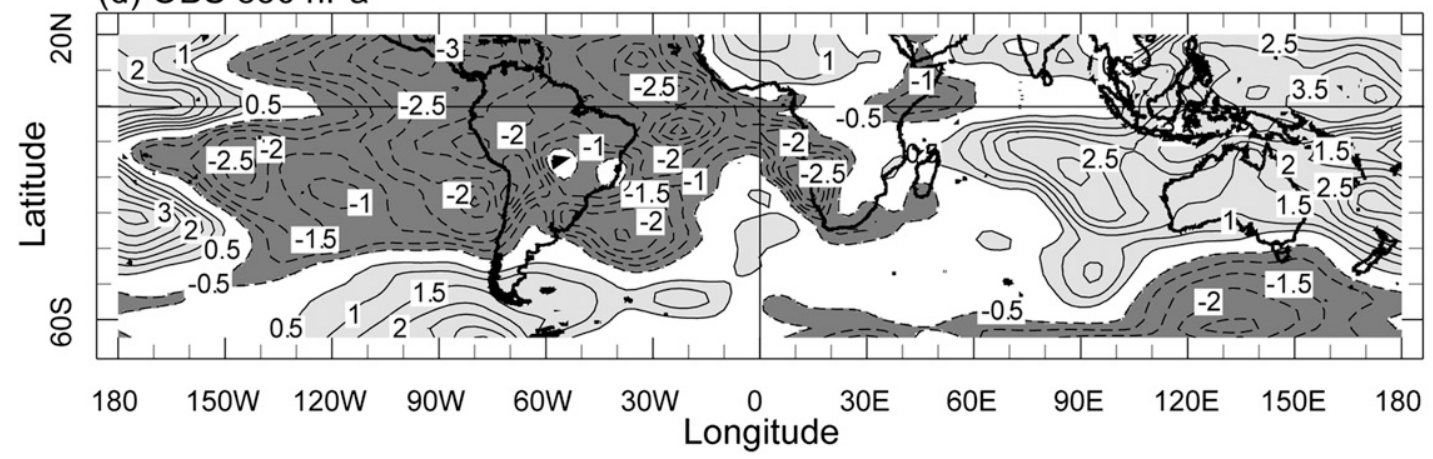

FIG. 6. Standardized anomalies of $850-\mathrm{hPa}$ geopotential height departures from zonal average for the AGCMs and in observations. Light (dark) shading indicates anomalies above (below) 0.5 standard deviations. 

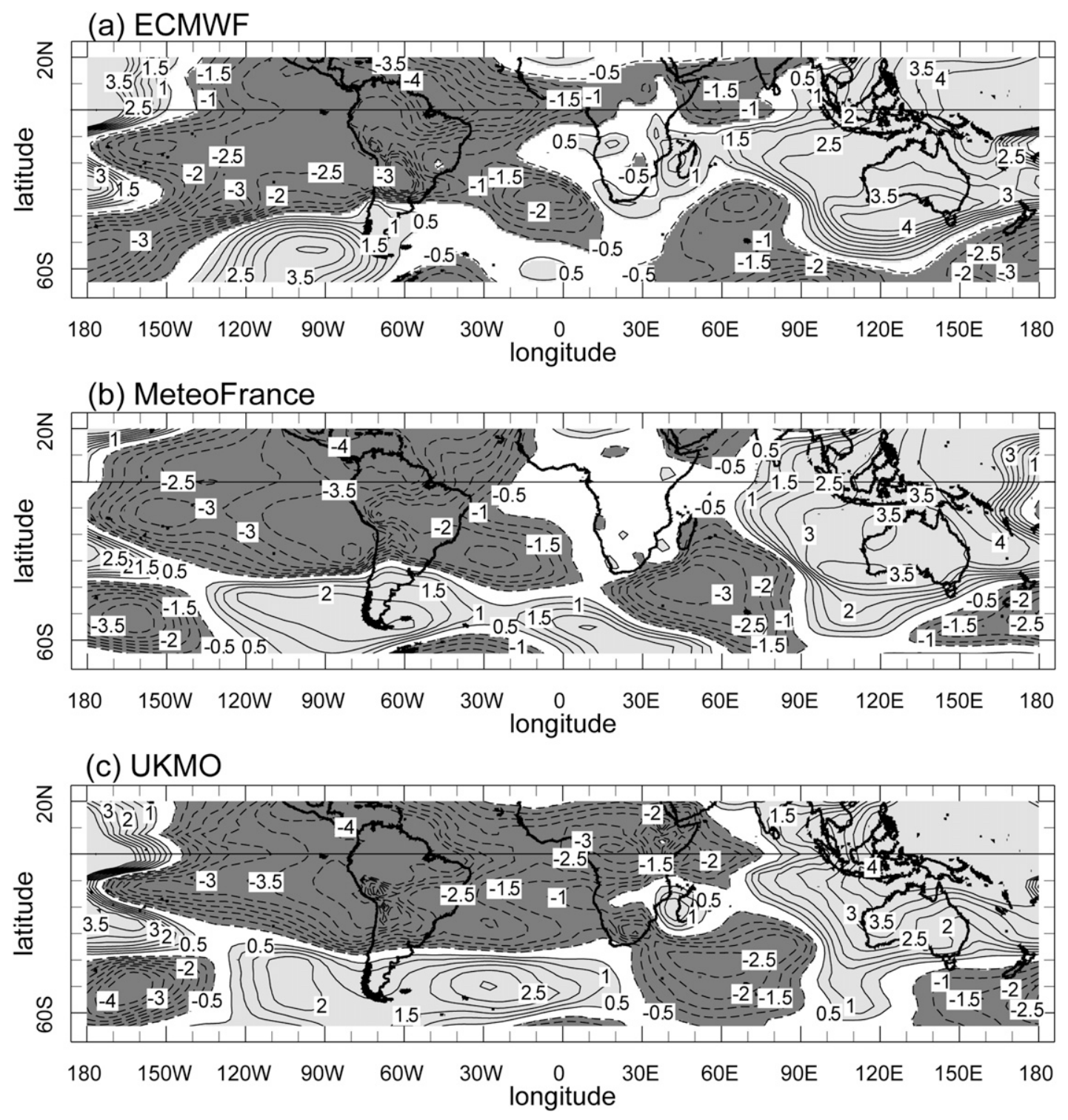

FIG. 7. As in Fig. 6, but for the coupled model forecasts.

As noted in Part I, the anomalous 200-hPa stationary wave pattern across the South Atlantic in JFM 1998 was suggestive of a wave train emanating from the midlatitudes east of Argentina with an associated downstream anomalous cyclonic circulation possibly linked to an enhanced Angola low. Further evidence for this wave train is shown in Fig. 8a, where the JFM 1998 200-hPa anomalous stationary wave pattern is plotted along with $\mathbf{F}_{\mathbf{s}}$ vectors, based on reanalysis data, which indicate an anomalous wave train extending across the South Atlantic. For comparison with 1998, Fig. 8b shows the composite, anomalous stationary wave pattern and $\mathbf{F}_{\mathbf{s}}$ vectors at $200 \mathrm{hPa}$ for JFM of the composite El Niño (excluding 1998). As described in Part I, the composite wave patterns for the seven previous El Niño events over the South Atlantic (and Pacific) are markedly different from JFM 1998. In the current study it was desired to see how well the AGCMs and coupled models performed in generating generally similar wave patterns to those observed in JFM 1998 in these regions.

Figure 9 shows the ensemble mean, anomalous stationary waves, and $\mathbf{F}_{\mathbf{s}}$ vectors for JFM 1998 computed from the AGCM simulations. The observed, anomalous wave train across the South Atlantic to the west coast of southern Africa is notably absent in all three models, which all extend an anomalous ridge from the central South Atlantic across southern Africa. The AGCMs also generate anomalous cyclonic circulations over the 
(a) Reanalysis JFM 1998

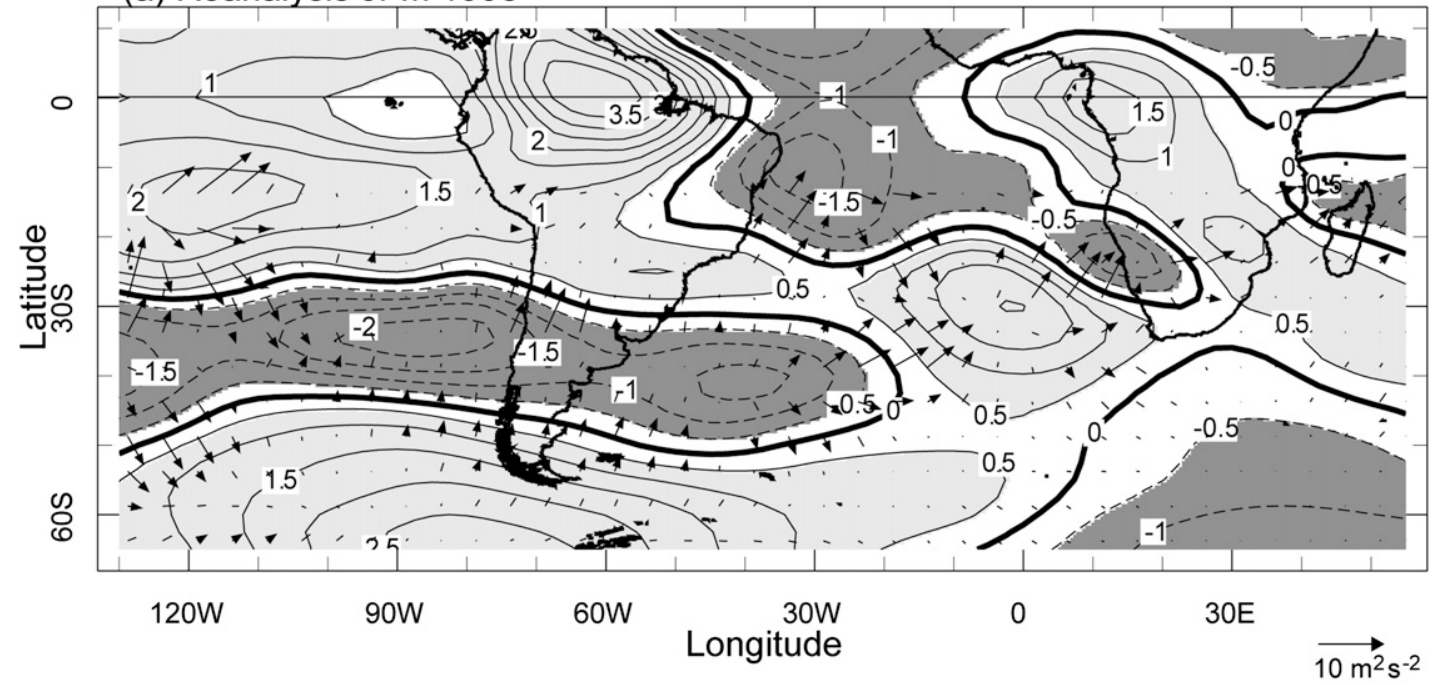

(b) Reanalysis JFM Composite

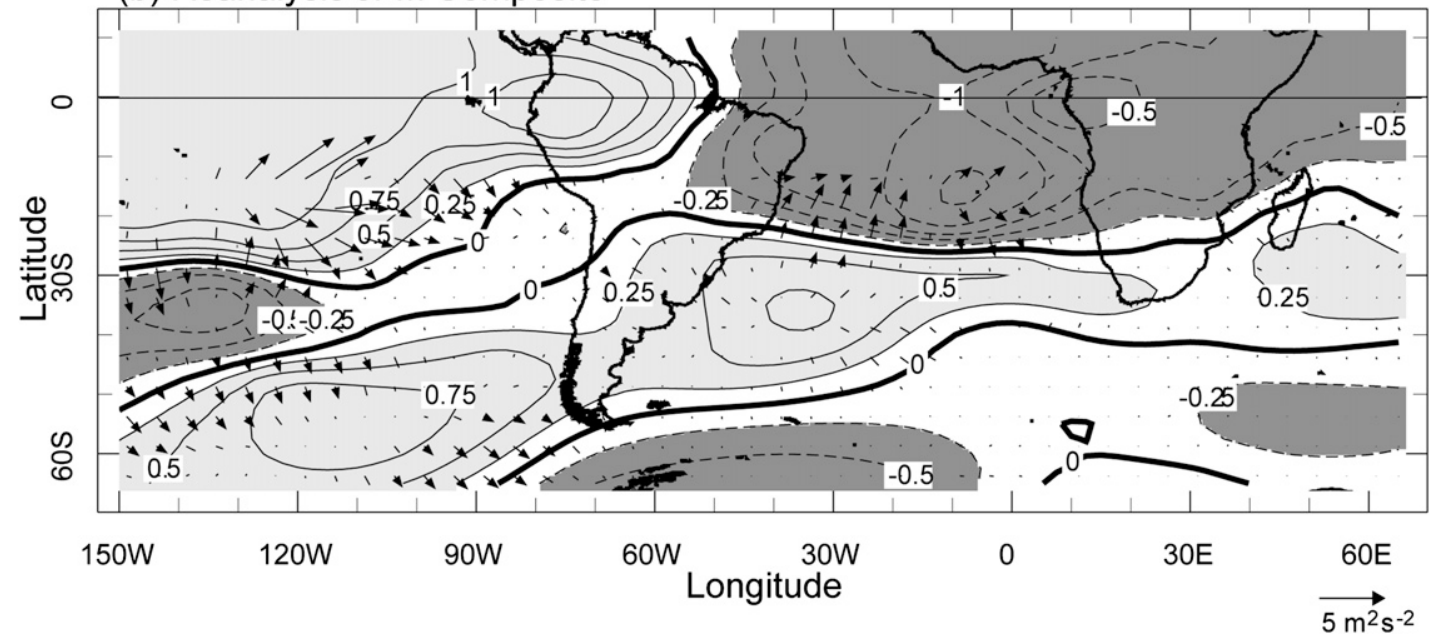

FIG. 8. Standardized anomalies of the 200-hPa stationary waves (contours) and $\mathrm{F}_{\mathrm{s}}$ vectors (units: $\mathrm{m}^{2} \mathrm{~s}^{-2}$ ) in the reanalysis for (a) JFM 1998 and (b) JFM composite for the seven El Niño events. Vector scale shown below (a) and (b); light (dark) shading indicates anomalies above (below) 0.5 standard deviations.

southern Indian Ocean centered near $50^{\circ} \mathrm{S}, 50^{\circ} \mathrm{E}$, which is some $15^{\circ}$ latitude north of the observed counterpart (cf. Fig. 8a). This circulation feature exhibits a barotropic vertical structure given its approximate collocation with similarly signed $850-\mathrm{hPa}$ anomalies, shown in Fig. 6. The northern flank of this low-level circulation feature is associated with the anomalous westerly moisture flux south of Madagascar in the AGCMs shown in Fig. 4, but is not seen in the observations (cf. Part I, Fig. 3a). The anomalous westerly moisture flux generated by the AGCMs favors dry conditions in southern Africa because it opposes the climatological flux into the region from the southwest Indian Ocean (D'Abreton and Lindesay 1993; D'Abreton and
Tyson 1995, 1996). The ECPC model (Fig. 9c) shows markedly different behavior from the other two AGCMs and observations in the eastern Pacific and South Atlantic.

The 200-hPa anomalous stationary waves and $\mathbf{F}_{\mathbf{s}}$ vectors for JFM 1998 in the coupled models are plotted in Fig. 10. Again the observed anomalous wave train across the South Atlantic to southern Africa is not evident in any of the models. In addition, Fig. 10 indicates that the coupled models generally generate too strong a wave train from the eastern South Pacific across central South America to the tropical Atlantic compared with JFM 1998 (or the composite El Niño). Similar to the AGCMs, the coupled models generate an anomalous 
(a) CCM $3.6200 \mathrm{hPa}$

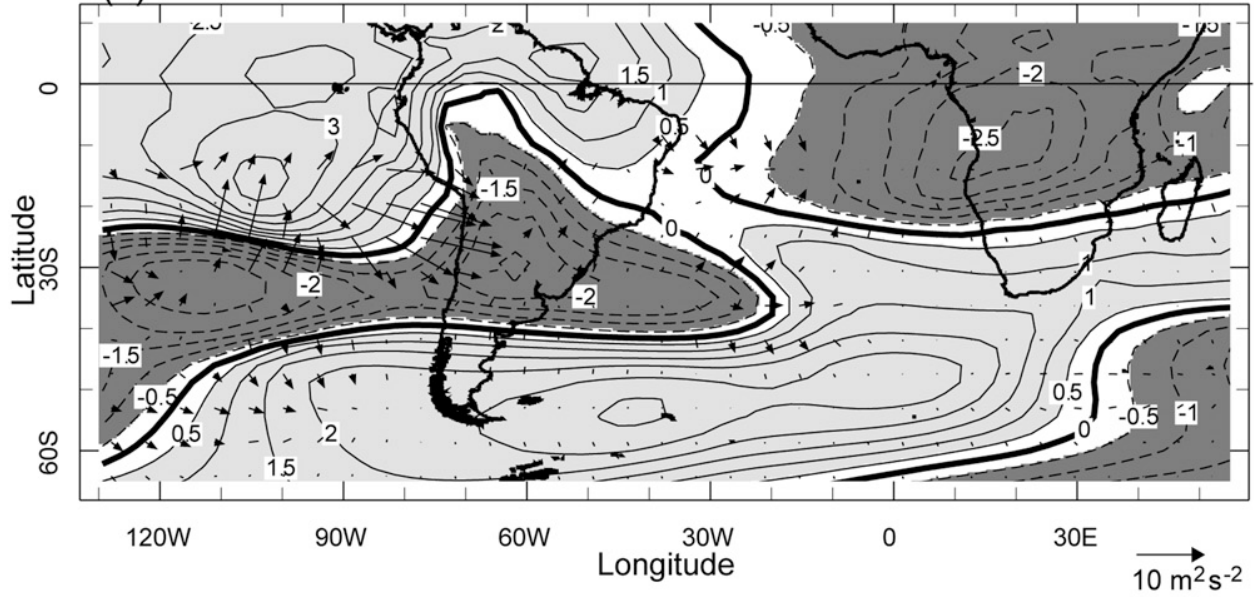

(b) ECHAM4.5 $200 \mathrm{hPa}$

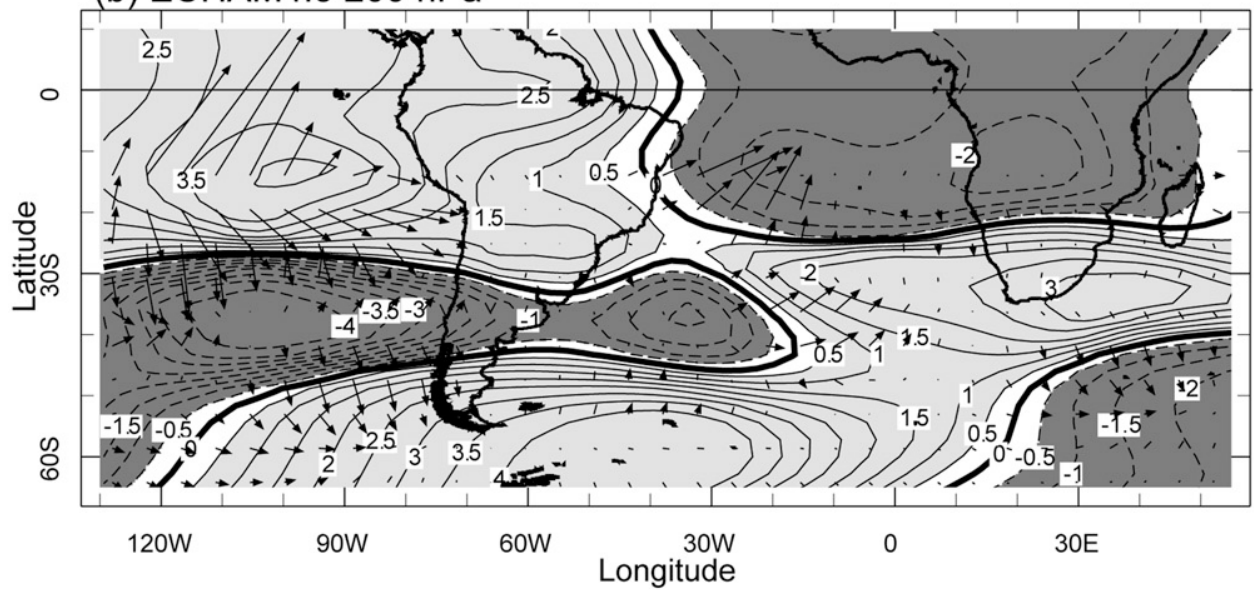

(c) ECPC $200 \mathrm{hPa}$

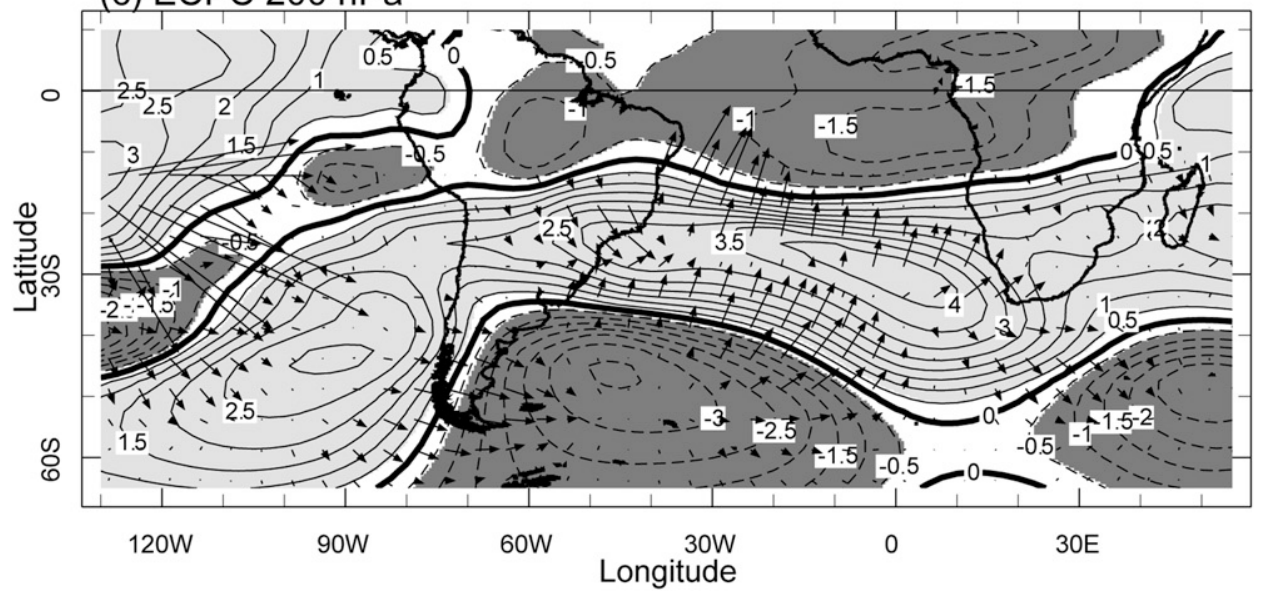

FIG. 9. As in Fig. 8, but for JFM 1998 in the AGCMs.

ridge over southern Africa and anomalous cyclonic circulations to the southeast of Madagascar (near $50^{\circ} \mathrm{S}$, $50^{\circ} \mathrm{E}$ ), which again exhibits a barotropic vertical structure. The primary difference between the AGCMs and the two coupled models showing a somewhat enhanced likelihood for wetter conditions than in past El Niño events is therefore the latter models' behavior over the Indian Ocean, which favored an enhanced flux of 
(a) ECMWF $200 \mathrm{hPa}$

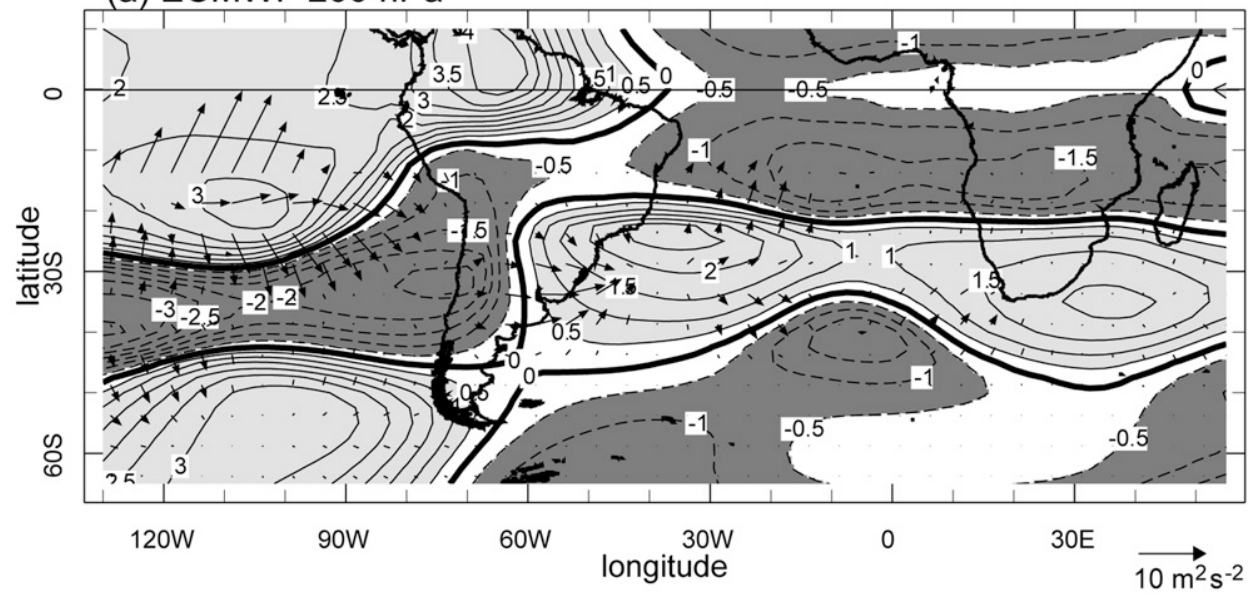

(b) MeteoFrance $200 \mathrm{hPa}$

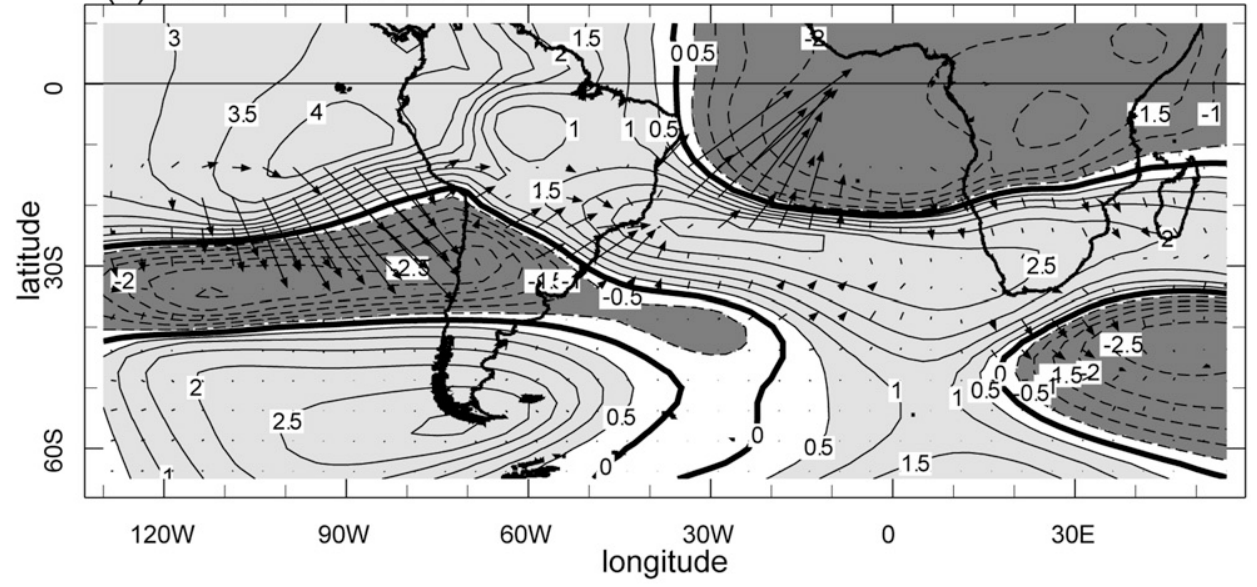

(c) UKMO $200 \mathrm{hPa}$

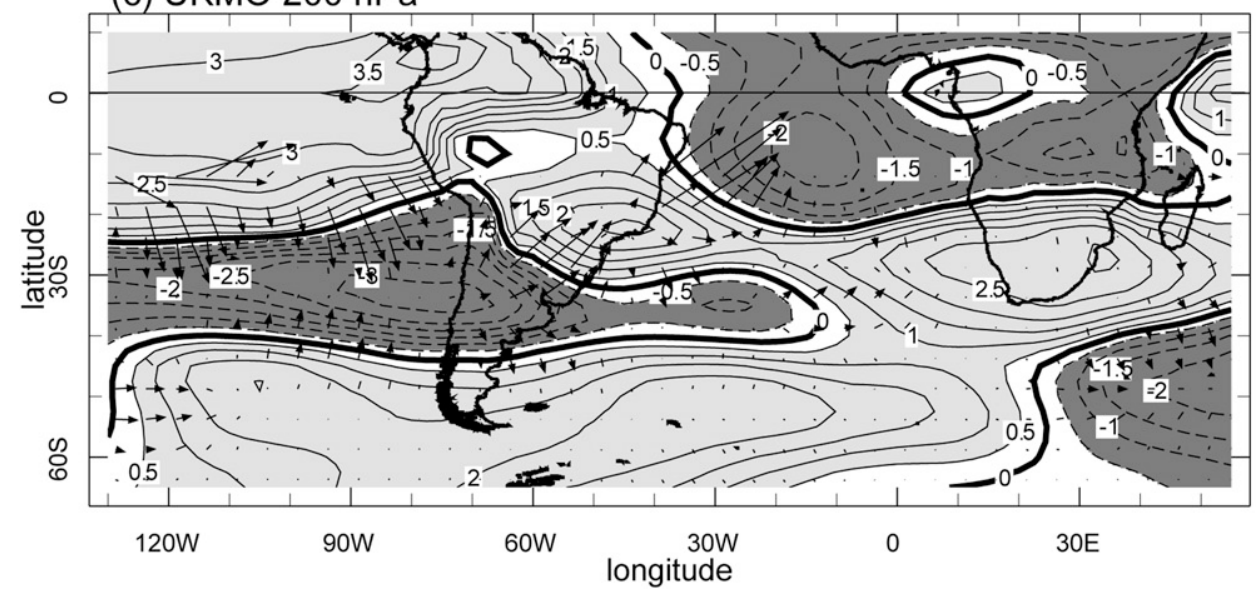

FIG. 10. As in Fig. 9, but for JFM 1998 in the coupled model forecasts.

low-level moisture from the western part of the basin into southern Africa.

Because the coupled models generate their own SST fields, comparisons of this field were made between the two "wetter" models and the model that generated comparatively dry conditions across southern Africa. Standardized SST anomalies for the coupled models and observations are shown (Fig. 11). All three models 

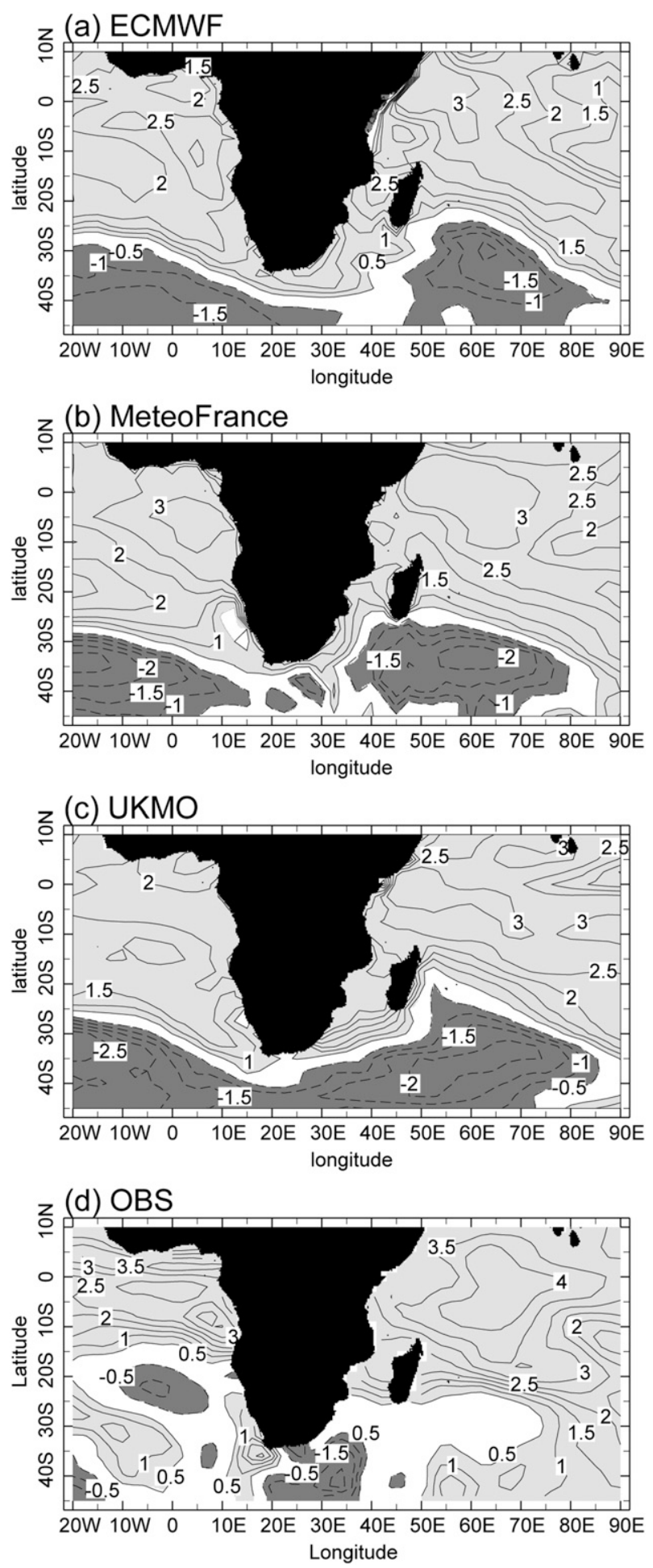

FIG. 11. Standardized SST anomalies for JFM 1998 for the three coupled models and in observations. Dark (light) shading indicates negative (positive) anomalies. generate anomalously high SSTs in the tropical western Indian Ocean and through the Mozambique Channel, and negative anomalies to the southeast of Madagascar. This latter feature is consistent with the anomalous 850-hPa circulations in these models shown in Fig. 7. In terms of gradients in the full SST field (not shown) in the coupled models, each generated spatial patterns in the western Indian Ocean for JFM 1998 that projected strongly onto the seasonal pattern of SSTs during past El Niño events in the models based on empirical orthogonal function (EOF) analysis.

\section{Discussion and conclusions}

Overall, the AGCM simulations were able to capture the enhanced rainfall in tropical East Africa in JFM 1998, while generally being unable to generate observed rainfall conditions across southern Africa. This finding is consistent with the modeling study of the 1997/98 El Niño by Su et al. (2001) who used the quasi-equilibrium tropical circulation model (QTCM) to examine the atmospheric response to observed JFM 1998 SST anomalies in the Indian Ocean (climatological SST elsewhere). The largest response to this forcing in their model was over the western Indian Ocean and Africa, including enhanced rainfall in tropical East Africa and relatively weaker drier-than-average conditions across southern Africa. The $850-\mathrm{hPa}$ wind response in their model also indicated the development of an anomalous cyclonic circulation to the east of Madagascar, which is typical of the composite El Niño, but which was not observed in JFM 1998. When JFM 1998 SST anomalies from all tropical oceans were used to force the model, the rainfall signal across southern Africa was somewhat drier than for the Indian Ocean-only forcing, while farther to the north the positive rainfall anomalies across eastern Africa were reduced in magnitude. This result is similar to that found in the isolated basin model experiments by Goddard and Graham (1999) for the NovemberJanuary (NDJ) season of the 1982/83 El Niño, where isolated forcing from tropical Pacific SST anomalies were shown to generate an opposite response in rainfall in eastern Africa than did those only in the Indian Ocean, while in southern Africa SST forcing from both regions was of the same sign. Qualitatively similar results were also found by Latif et al. (1999) in their modeling study of the 1997/98 El Niño in which they also concluded that the Indian Ocean SSTs were essential to generating the unusually wet conditions across East Africa, but their model also generated drier-thanaverage conditions across southern Africa.

Were the marked differences in modeled versus observed rainfall over southern Africa in JFM 1998 a 
result of random, unpredictable processes, or are the AGCMs simply not responding properly to the observed SSTs? This study suggests a combination of these two factors. For example, over the eastern Indian Ocean north of roughly $20^{\circ} \mathrm{S}$ and east of $75^{\circ} \mathrm{E}$ unusually dry conditions were observed in JFM 1998 (Fig. 12a), while the AGCMs generated generally enhanced rainfall there (Figs. 12b-d). This discrepancy in turn appears to be related to the inability of the AGCMs to generate the proper intensity and location of the anomalous lowlevel anticyclonic circulation over the central Indian Ocean, and therefore the anomalous flux of moisture into southern Africa during JFM 1998. Also, the confluence zone with enhanced rainfall, which in the observations extends from Kenya southeastward to roughly $30^{\circ} \mathrm{S}, 90^{\circ} \mathrm{E}$, is not similarly reproduced by the AGCMs. The two "wetter" coupled models used here were able to more realistically capture the large-scale anomalous rainfall (Fig. 13) and circulation patterns over the Indian Ocean and moisture flux into southern Africa.

Both sets of models, however, did not generate anomalous stationary wave patterns over the South Pacific and Atlantic Oceans, consistent with the observations. The observed anomalous wave train over the South Atlantic in JFM appears to have been associated with an enhanced Angola low, which was responsible for an enhanced moisture flux into southern Africa from the tropical interior, and, to a lesser extent, the tropical Atlantic in JFM 1998. The lack of an anomalous cyclonic circulation over the southern Indian Ocean to the southeast of Madagascar in JFM 1998 appears to be related to the anomalous stationary wave pattern across the Southern Hemisphere, which the models did not capture well. In a GCM study of the Southern Hemisphere anomalous wave response to El Niño (for the month of December), Cook (2001) argues that the appearance of a similar anomalous cyclonic circulation southeast of Madagascar is related to local forcing from a northeastward shift in convection from over southern Africa to the southwest Indian Ocean. Here such a relationship is not clear, because the anomalous cyclonic circulation southeast of Madagascar appears in the AGCMs, which generated the more typical rainfall ENSO response over southern Africa, as well as in the two coupled models that were comparatively wet. In addition, the $\mathbf{F}_{\mathbf{s}}$ vectors in Figs. 9 and 10 suggest that this circulation feature is also associated with anomalous stationary wave activity farther upstream. In any case, it appears that the observed anomalous stationary waves in the Southern Hemisphere in JFM 1998 were either at least partially a result of internal atmospheric variability, and were unpredictable on seasonal time scales, or the models may have simply been unable to capture this behavior if it was indeed related in some way to anomalous SSTs.

Another possibility is that while ensemble averaging helps filter random "weather noise" from a seasonal ENSO signal, there are often systematic biases in the model circulation and precipitation fields that also need to be considered. Such biases can be reduced through application of statistical methods, such as canonical correlation analysis (CCA). Such an approach has been applied to AGCM output in predictability studies of southern Africa rainfall in two-tier prediction schemes (Landman and Mason 1999; Landman and Goddard 2002, 2005). In their analysis of the predictability of southern Africa summer (DJF) rainfall, Landman and Goddard (2002, 2005) showed the leading CCA predictor field was 850 -hPa geopotential height anomalies located over the southern Africa subcontinent, which had a pattern quite similar to the regional $850-\mathrm{hPa}$ anomalous geopotential fields shown here for the AGCMs in Fig. 6. This pattern, however, although characteristic of the composite El Niño, was not observed in JFM 1998. As such, it is anticipated that the seasonal rainfall forecast for DJF 1997/98 from their model would have tended to be too dry, as was the case for the "raw" model simulation results shown here.

In conclusion, the results of this modeling study indicate that AGCMs forced with observed, global, SSTs were unable to generate the wetter-than-average conditions observed in southern Africa in JFM 1998 compared with the JFM season during the seven past El Niño events. Two of the three coupled models performed somewhat better in this regard, but none of the models were able to generate an anomalous Angola low that Part I and Reason and Jagadheesha (2005) found to be important to the relative increase in southern African rainfall in 1998. More generally, the anomalous Southern Hemisphere stationary waves were well captured neither by the AGCMs nor the coupled models, although there were some indications that two of the coupled models were able to realistically capture the observed large-scale anomalous pattern over the Indian Ocean. The failure of the models to capture the anomalous stationary wave patterns in JFM 1998 may indicate that 1) the models are unable to capture important aspects of anomalous boundary forcing via SSTs, 2) the anomalous stationary waves in JFM 1998 were (at least partially) unpredictable, or 3) some combination of the two. Would the observed rainfall conditions in southern Africa in JFM 1998 have been foreseeable if "perfect" SST information (i.e., observations) were available a season ahead? This study indicates the answer is "no," at least with current-generation AGCMs used in a twotier prediction system. 


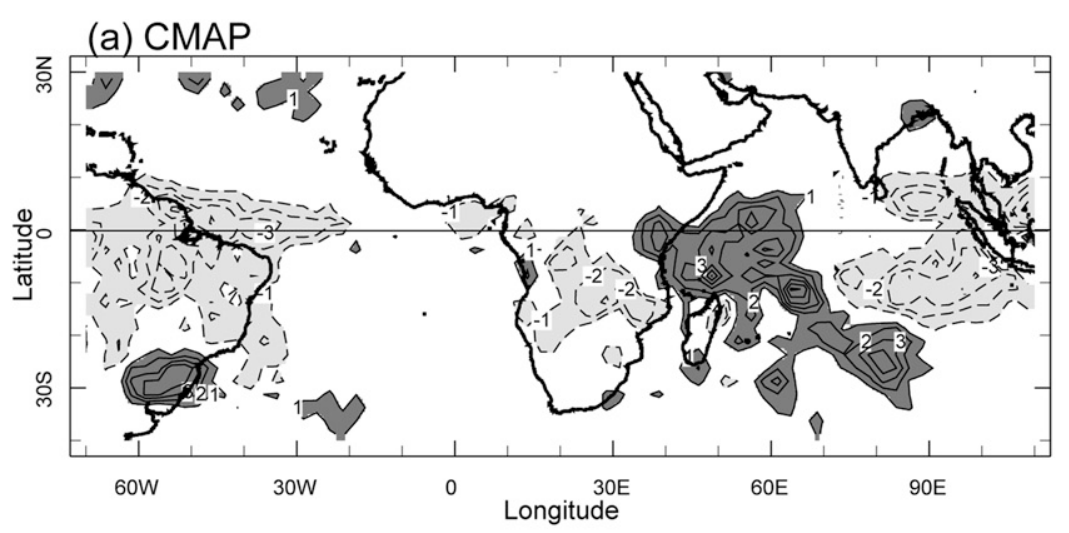

(b) CCM3.6

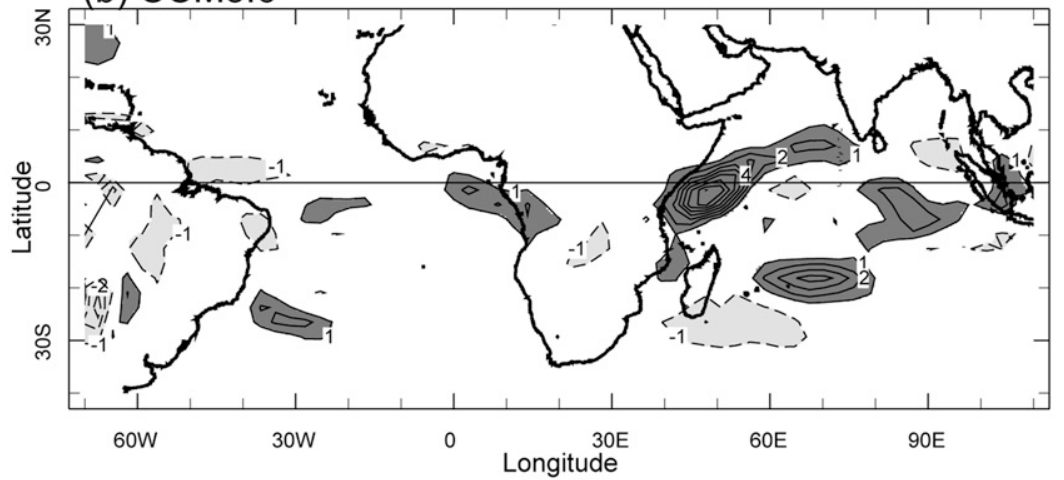

(c) ECHAM4.5

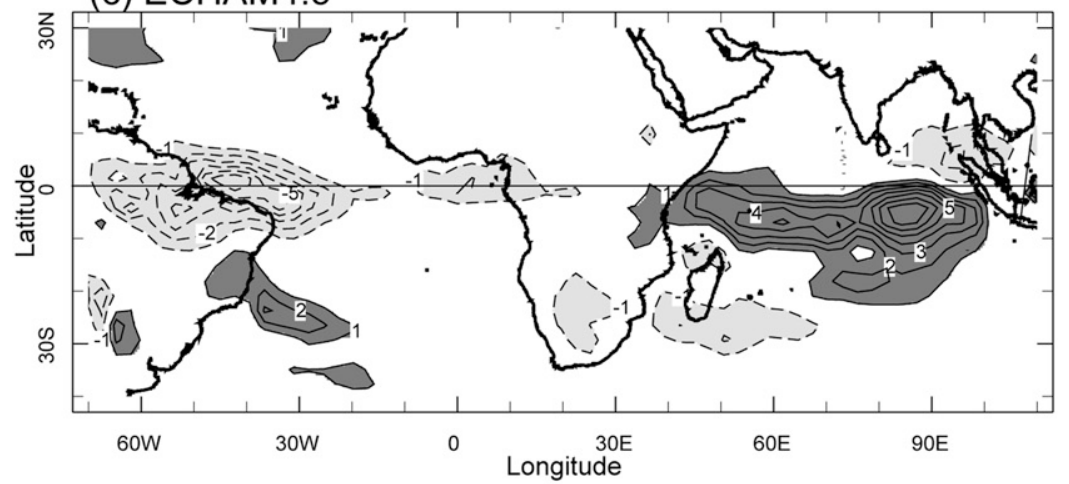

(d) ECPC

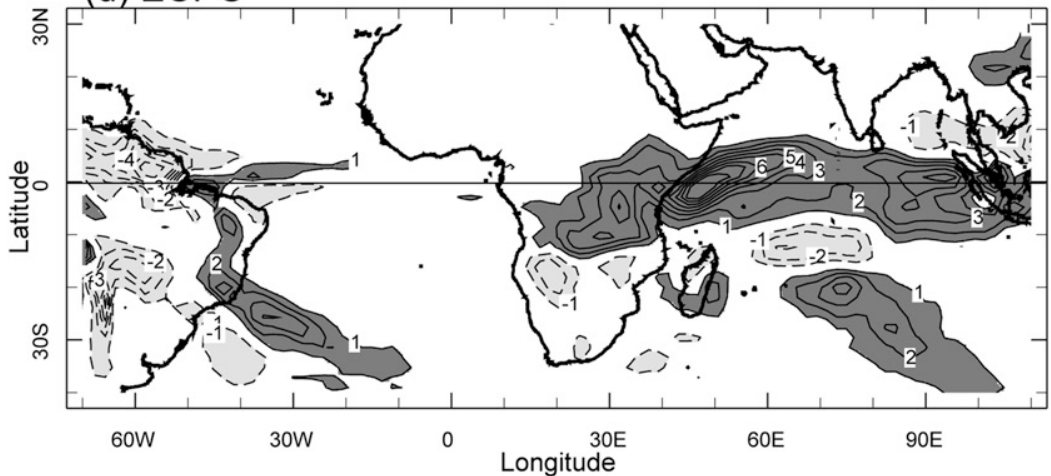

FIG. 12. JFM 1998 rainfall anomalies (units: $\mathrm{mm} \mathrm{day}^{-1}$ ) for (a) CMAP and (b)-(d) AGCMs. Dark (light) shading indicates positive (negative) anomalies. 


\section{(a) ECMWF}

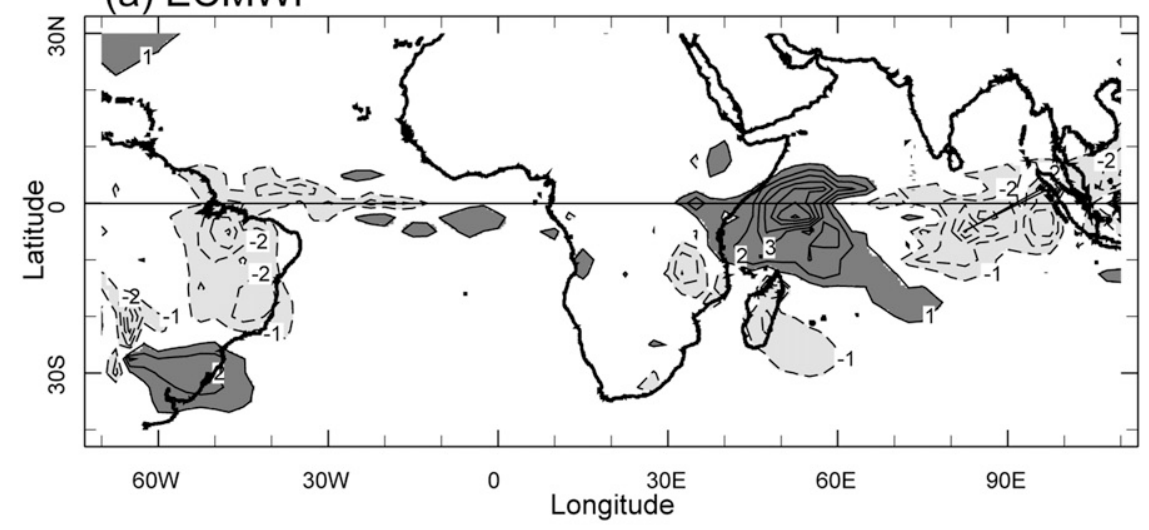

(b) MeteoFrance

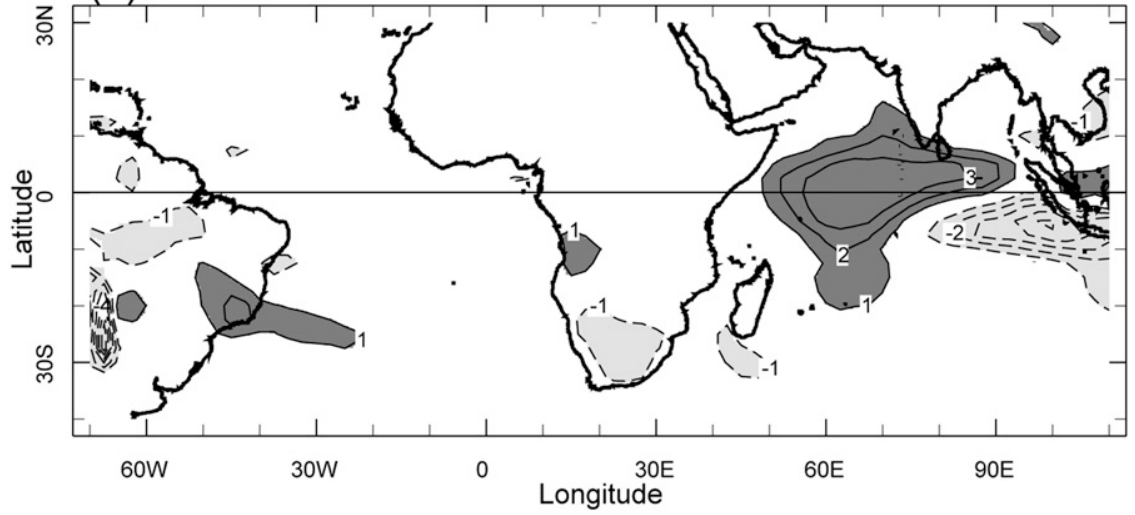

(c) UKMO

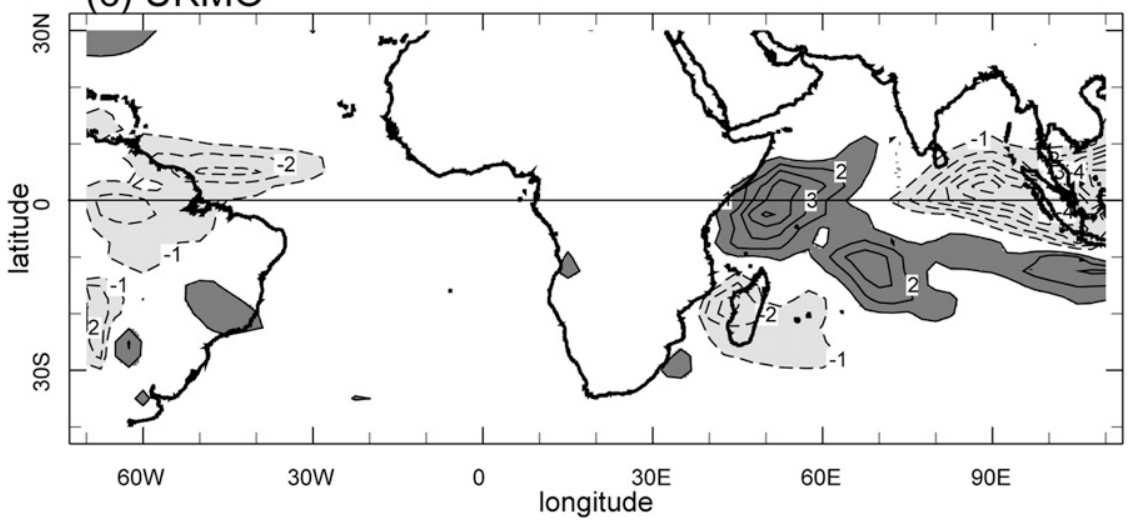

FIG. 13. As in Fig. 12, but for only the coupled model forecasts.

Acknowledgments. This work was funded by Cooperative Agreement NA050AR4311004 from the National Oceanic and Atmospheric Administration (NOAA). The ECHAM version 4.5 simulations were generated by D. DeWitt, X. Gong, S. Li, and L. Goddard, International Research Institute for Climate and Society, with computer resources provided in part by the NCAR CSL. The authors also thank A. G. Barnston for comments on an earlier version of this manuscript. The views expressed herein are those of the authors, and do not necessarily reflect the views of NOAA or any of its subagencies.

\section{REFERENCES}

Berbery, E. H., J. Nogués-Paegle, and J. D. Horel, 1992: Wavelike Southern Hemisphere extratropical teleconnections. J. Atmos. Sci., 49, 155-177.

Cook, C., C. J. C. Reason, and B. C. Hewitson, 2004: Wet and dry spells within particularly wet and dry summers in the South African summer rainfall region. Climate Res., 26, 17-31. 
Cook, K. H., 2001: A Southern Hemisphere wave response to ENSO with implications for southern Africa precipitation. $J$. Atmos. Sci., 58, 2146-2162.

D'Abreton, P. C., and J. A. Lindesay, 1993: Water vapour transport over southern Africa during wet and dry early and late summer months. Int. J. Climatol., 13, 151-170.

— vapour transport over southern Africa during wet and dry conditions. Meteor. Atmos. Phys., 55, 47-59.

—, and —, 1996: Three-dimensional kinematic trajectory modelling of water vapour transport over southern Africa. Water S. Afr., 22, 297-305.

Goddard, L., and N. E. Graham, 1999: Importance of the Indian Ocean for simulating rainfall anomalies over eastern and southern Africa. J. Geophys. Res., 104, 19 099-19 116.

Kanamitsu, M., and Coauthors, 2002: NCEP dynamical seasonal forecast system 2000. Bull. Amer. Meteor. Soc., 83,1019-1037.

Kiehl, J. T., J. J. Hack, G. B. Bonan, B. A. Boville, D. L. Williamson, and P. J. Rasch, 1998: The National Center for Atmospheric Research Community Climate Model: CCM3. J. Climate, 11, 1131-1149.

Kistler, R., and Coauthors, 2001: The NCEP-NCAR 50-Year Reanalysis: Monthly means CD-ROM and documentation. Bull. Amer. Meteor. Soc., 82, 247-268.

Landman, W. A., and S. J. Mason, 1999: Operational long-lead prediction of South African rainfall using canonical correlation analysis. Int. J. Climatol., 19, 1073-1090.

—, and L. Goddard, 2002: Statistical recalibration of GCM forecasts over southern Africa using model output statistics. J. Climate, 15, 2038-2055.

$\longrightarrow$, and —, 2005: Predicting southern Africa summer rainfall using a combination of MOS and perfect prognosis. Geophys. Res. Lett., 32, L15809, doi:10.1029/2005GL022910.

Latif, M., D. Dommenget, M. Dima, and A. Grötzner, 1999: The role of Indian Ocean sea surface temperature in forcing East African rainfall anomalies during December-January 1997/98. J. Climate, 12, 3497-3504.

Lyon, B., and R. M. Dole, 1995: A diagnostic comparison of the 1980 and 1988 U.S. summer heat wave-droughts. J. Climate, 8, $1658-1675$.

, and S. J. Mason, 2007: The 1997-98 summer rainfall season in southern Africa. Part I: Observations. J. Climate, 20, 51345148 .
Mason, S. J., and M. R. Jury, 1997: Climatic variability and change over southern Africa: A reflection on underlying processes. Prog. Phys. Geogr., 21, 23-50.

— alies associated with ENSO. Bull. Amer. Meteor. Soc., 82, 619-638.

New, M., M. Hulme, and P. D. Jones, 1999: Representing twentiethcentury space-time climate variability. Part I: Development of a 1961-90 mean monthly terrestrial climatology. J. Climate, 12, 829-856.

$\ldots, \ldots$, and — 2000: Representing twentieth-century space-time climate variability. Part II: Development of 1901-96 monthly grids of terrestrial surface climate. J. Climate, 13, 2217-2238.

— M. Todd, M. Hulme, and P. D. Jones, 2001: Precipitation measurements and trends in the twentieth century. Int. J. Climatol., 21, 1899-1922.

Palmer, T. N., and Coauthors, 2004: Development of a European Ensemble System for Seasonal to Interannual Prediction (DEMETER). Bull. Amer. Meteor. Soc., 85, 853-872.

Plumb, R. A., 1985: On the three-dimensional propagation of stationary waves. J. Atmos. Sci., 42, 217-229.

Reason, C. J. C., and D. Jagadheesha, 2005: A model investigation of recent ENSO impacts over southern Africa. Meteor. Atmos. Phys., 89, 181-205.

Roeckner, E., and Coauthors, 1996: The atmospheric circulation model ECHAM-4: Model description and simulation of present-day climate. MPI für Meteorologie MPI-Rep. 218, $90 \mathrm{pp}$.

Rouault, M., and Y. Richard, 2003: Intensity and spatial extension of drought in South Africa at different time scales. Water S. Afr., 29, 489-500.

Sheskin, D. J., 2007: Handbook of Parametric and Nonparametric Statistical Procedures. Chapman \& Hall/CRC, 1776 pp.

Su, H., D. J. Neelin, and C. Chou, 2001: Tropical teleconnection and local response to SST anomalies during the 1997-1998 El Niño. J. Geophys. Res., 106, 20 025-20 043.

Todd, M., and R. Washington, 1999: Circulation anomalies associated with tropical-temperate troughs in southern Africa and the southwest Indian Ocean. Climate Dyn., 15, 937-951.

Xie, P., and P. A. Arkin, 1996: Analysis of global monthly precipitation using gauge observations, satellite estimates, and numerical model predictions. J. Climate, 9, 840-858. 